\title{
Application of Case Teaching Method in Computer English Teaching under OBE Mode
}

\author{
Yu Sun ${ }^{1}$ \\ ${ }^{1}$ Shandong Xiehe University-Ji Nan-Shan Dong-China,250109
}

\begin{abstract}
The author of this paper analyzes and studies the problems in the current computer English teaching. At the same time, this article also discusses the application strategy of case teaching method in computer English teaching under OBE mode. Therefore, the method proposed by the author in this article can improve the teaching efficiency and teaching level of computer English to a certain extent.
\end{abstract}

\section{Overview of OBE Mode}

In the application process of the OBE model, it is more emphasized that the educated person should be guided by the effect of learning in the learning process. The main working principle of the OBE model is that after analyzing the actual learning effects of students, educators formulate talent training programs and teaching evaluation systems according to the specific needs of learners. In the course of education, educators must ensure the clarity of teaching objectives, and at the same time make preliminary predictions of learning outcomes. For example, in the teaching of computer English courses, teachers need to conduct data analysis according to the development of market economy. Moreover, teachers should set teaching goals based on computer language and other industries requiring for students that they need to master English vocabulary and phrase level. At the same time, educators need to carry out link setting and implementation according to the specific conditions of students in the learning process. The biggest difference between the OBE model and the traditional education model is that during the development process, students are considered to be the protagonists of the entire teaching process. Teachers must enable students to clearly understand what they need to do, what learning tasks they need to be completed, and how students should work with group members in order to complete learning tasks. In the whole teaching, teachers are only the enlightenment of students' learning and the regulator of the learning process. After the students complete the learning tasks, the teacher also needs the students as the main body to design a multi-party participation evaluation mechanism. Only in this way can the teaching effect be maximized [1].

\section{Overview of Case Teaching}

The application of case teaching method in the process of carrying out educational activities can improve teaching efficiency to a certain extent. Because before implementing teaching activities, educators need to select cases related to teaching goals based on pre-set teaching goals. Then, teachers can use different forms to guide students, so that students can independently analyze and discuss through the case. Otherwise, in the case teaching process, teachers need to require students to be able to judge and make decisions on the problems in the case based on the case content. Generally, case teaching methods include the following three categories: First, analyze and understand the case. In this case teaching process, teachers need to give cases and propose problems and solutions. At the same time, the teacher should allow students to analyze the problems in the case in the process of understanding and mastering the case, and clarify the thinking of solving the problem. Second, evaluate decision-making cases. In this case teaching process, in addition to giving student cases, teachers also provide corresponding solutions. Then, students can investigate and evaluate the solutions in the form of individuals or groups. Finally, students determine the best decision-making plan through the comparing and analyzeing the different solutions. Third, cite one case. The main purpose of this case teaching is that students can learn the theory of knowledge they need to master through the study of typical cases, and use the corresponding theoretical knowledge to solve problems. In addition to accurately understanding the students' learning ability, teachers need to accurately understand the students' learning ability. More importantly, they need to mobilize the students' subjective initiative so that students can actively participate in the case discussion and research process. In addition, teachers must give the classroom to students, and encourage students to solve problems by themselves, which is the biggest purpose of case teaching method [2].

In the application of case teaching method, we must adhere to the student's subjective status. Teachers should be mainly inspired and guided in classroom teaching, 
which is an important factor to ensure the successful application of case teaching methods. Constructivist theory and case teaching are complementary. The information provided by the constructivist theory in the case analysis process can create a problem situation with a strong sense of substitution for the students, and then allow the students to discuss and study the solution of the problem in the problem situation. Using this method can fully stimulate students' initiative and enthusiasm in participating in learning, and improve students' independent learning ability and cooperative communication ability. For example, in the teaching process of evaluating decision-making cases, students must pass specific data analysis and control evaluation to accurately analyze and investigate different cases. In addition, students need to compare cases to obtain the optimal decision-making plan. Moreover, when investigating and analyzing the plan, collaboration and communication between the teams can promote the improvement of the student's knowledge system.

\section{Features of Computer English}

In the process of rapid development of computer technology, the development of big data technology, Internet of Things technology and artificial intelligence and other technologies are relatively rapid. The development of these technologies is based on the compilation of English language. This shows that in the development of computer-related technology, the level of English will affect the professional ability of computer technology talents to a certain extent. Therefore, we must pay attention to the teaching of computer English in the teaching process of computer science. The characteristics of computer English are mainly manifested in the following aspects: First, the use of computer professional vocabulary is relatively small. These vocabularies are only confined to the industry and do not create ambiguity. Computer language has a large number of proper nouns in the application process, and it also uses a large number of interdisciplinary vocabulary and extended vocabulary. Besides, computer English vocabulary and English use the same form of acronyms. The terminology of computer is generally applied in the computer specialty and related fields. For example, big data, algorithms, network security, and cloud computing all apply to computer proper nouns. When learning these proper nouns, the students' recitation tasks are more arduous and the learning content is a bit boring. If the student's English foundation itself is not strong enough, this will increase the student's learning burden. But basic vocabulary is the focus of computer English teaching. Moreover the extended words and derived words in computer English are generally applied in multiple fields. The accumulation and absorption of extended words and derived words in the process of computer English learning is an important way to improve the English level of technical staff. In addition, the application of abbreviations and compound words is also more important. These vocabulary can not only improve the efficiency of information transmission, but also use abbreviations or compound words to carry more information capacity in the shortest time. Acronyms and compound words have different forms, but their common denominator is to simplify the lengthy words. Second, computer English sentence structure and translation characteristics. Computer English itself belongs to the category of academic English, which is mainly based on a large number of passive sentences in grammar, which can ensure the rigor of expression. However, due to the limitation of the size of the computer screen, the sentence structure of computer English needs to be more refined and objective. A large number of computer English texts appear not only in books and periodicals, but also in user interaction interfaces and computer product manuals. Therefore, when translating computer English, except completely and rigorously translate passive sentences, inverted sentences, and short and long sentences, students should also ensure that the audience can understand English sentences accurately according to the goals of the text. In addition, students should ensure that the translated text reduces the difficulty of understanding as much as possible and improve the readability of computer English translation results [3].

\section{Application Status of Computer English Teaching}

There are some difficulties in the current computer English teaching process that will affect the efficiency and quality of computer English teaching. These difficulties are mainly manifested in the following aspects: First, from the perspective of social needs. The traditional universities are mainly based on the teaching of CET-4 and CET-6 or TEM-4 and TEM-8. Moreover, most computer software companies mainly use computer English CET-4 and CET-6 or TEM-4 and TEM-8certificates when hiring computer professionals. Only some multinational software companies will pay more attention to the professional capabilities of computer talents. However, in the development process of the computer industry, employees will still have different needs for their English ability because of their positions. Generally, the content of the responsibilities of primary and intermediate positions from programming to strategic management is basically based on basic reading and writing. In the work responsible for senior positions, it is more important to have strong business negotiation and cross-cultural communication skills. Therefore, when recruiting companies, they generally have certain requirements for the applicant's English application ability, and also use different interviews to find employees with innovative talents. For example, whether the candidate participates in the project operation or teamwork during the study. However, most of the colleges and universities use ordinary English teachers as computer English teaching when they carry out computer teaching, and mainly use traditional English teaching methods to carry out teaching. This will not only affect the students' interest in learning, but also cause many students to abandon the English learning process because of the too monotonous teaching methods and the 
insufficient English foundation. This is mainly because in the whole English learning process, students' sense of substitution, subjectivity and sense of accomplishment are relatively lacking. Second, in the course of computer English teaching, the correlation between the teaching material content and the computer major is not great. Because in most colleges and universities, computer English teaching is still carried out with the purpose of allowing students to obtain the CET-4 and CET-6 certificates. Most colleges and universities do not carry out targeted computer English teaching according to the interdisciplinary subjects involved in computer science. This will result in the lack of learning initiative and enthusiasm of the computer major students because they cannot effectively connect with the major when learning English. Eventually, this will cause students to feel bored and burdened with English courses, which seriously affects teaching efficiency [4].

\section{Application of Case Teaching Method in OBE Mode}

\subsection{Strengthen the Selection of Cases and Implement Basic Vocabulary Teaching}

In the course of computer English teaching, teachers should choose appropriate cases according to the specific teaching content, and use interest-driven to stimulate students' enthusiasm and initiative in understanding and mastering basic vocabulary. In computer English teaching, classroom cases are an important measure to improve classroom interest. In the process of developing computer professional English teaching, teachers can design pre-classes to guide the case, according to the frontier problems in the development process of the field of computer science, so that students have a strong sense of substitution when studying before class. At the same time, teachers should closely link the new content in the computer field with the teaching content. At this stage, students' interest and learning initiative in the computer field can be stimulated to a great extent. In addition, teachers can use multimedia materials to improve the fun of classroom teaching, bringing students practicality and enlightenment. Teachers can also use the new development of the computer field as an introduction point to incorporate proper nouns and basic vocabulary in the computer field into hot cases. This allows students to accurately grasp and understand basic vocabulary in the process of understanding the case.

\section{Establish A Comprehensive Scientific Evaluation System}

When using case teaching method to carry out computer English teaching in OBE mode, we must set up a more comprehensive and scientific evaluation and assessment system, so that we can accurately analyze and evaluate the effect of case teaching. After the design of the expected results of teamwork is completed, teachers need to conduct a comprehensive evaluation and assessment of the results. Teachers can ensure the comprehensive scientific nature of the assessment system according to the following: First, we must pay attention to the daily assessment, mid-term assessment and final examination of students. Under this evaluation system, teachers need to further refine the assessment content, and can accurately divide the scores of different parts according to different proportions according to the students' learning attitude, preschool analysis, professional knowledge base and practical ability. In addition, teachers can also adjust the score ratio according to their own experience. Second, when evaluating the participation of members, students must insist on mutual evaluation. At the same time, it is necessary to integrate the results of the students' mutual evaluation, which can improve the reliability of the evaluation results. Because in the teamwork, only the students themselves can accurately understand the contribution between students. During the assessment, teachers need to quantify the evaluation based on the assessment coefficient. Third, it is necessary to appropriately introduce enterprise experts to comment on the learning results of students. Teachers can use small seminars or remote video conferences to comment on students' learning outcomes. Because the introduction of enterprise experts will make students have a strong sense of professional substitution, allowing students to switch from the role of listening to the story to the role of the person in the picture, which can increase students' attention to assessment. The evaluation system of case teaching method under OBE mode is shown in Figure 1.

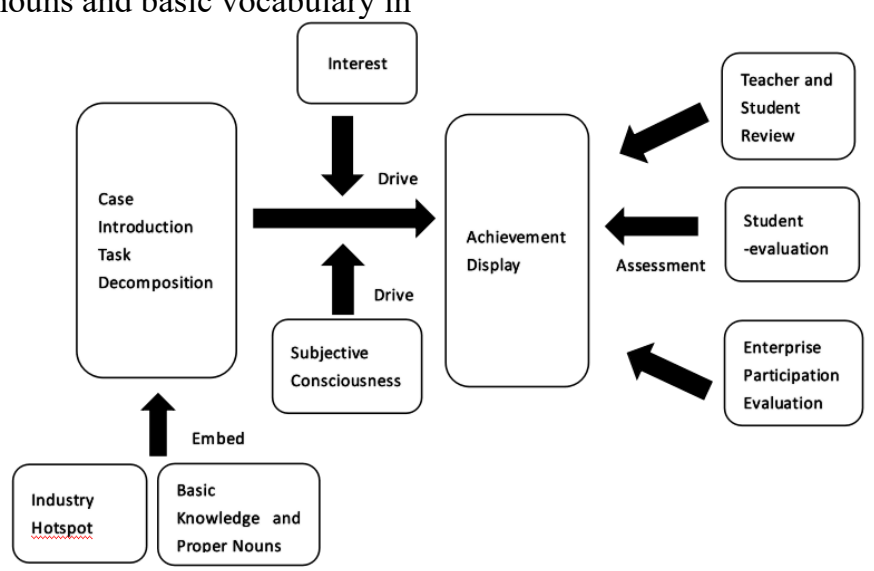

Figure 1 Case Evaluation Method Evaluation System under OBE Mode 


\section{Pay Attention to the Role of Teacher Guidance in Case Teaching}

When using case teaching method to carry out computer application teaching, teachers must actively change their roles, change traditional teaching concepts, guide students, and help students decompose learning tasks. At the same time, teachers should clarify the students' learning goals. In the process of formulating the computer English talent training program and curriculum syllabus, teachers need to complete the course design work based on students' learning attitude, pre-school analysis, professional knowledge base, and practical ability requirements. Teachers should ensure that the English teaching plan of the computer specialty course is compatible with the learning needs of students, ensure that English teaching and computer science can be effectively connected, and increase students' interest in learning and their sense of substitution in the learning process. In the process of setting the English teaching plan for the computer major, teachers should fully grasp the basic English vocabulary in various fields of computer science. These areas mainly include: second-generation data structure, database management, unit structure, operating system, computer language, software programming, network security, new media technology, etc. These areas can be understood as the decomposition process of learning outcomes [5].

\section{Conclusion}

In a word, using case teaching method to carry out computer English teaching in OBE mode can arouse students' subjective awareness in the learning process to a certain extent, which will actively help to cultivate students' independent learning ability and unity and cooperation ability. It should be noted that in the process of using the case teaching method, teachers should strengthen the close connection between the case and the teaching content, and let students think about the problem in the process of understanding and analyzing the case, and at the same time put forward related solutions to the problem. Only in this way can the purpose of improving the level of computer English teaching be achieved.

\section{References}

1. Cheng Dan, Ouyang Ting. Application of OBE-based inquiry model in English teaching in Chinese-foreign cooperative colleges and universities $[\mathrm{J}]$. Anhui Literature (second half of the month), 2017(11): 133-135.

2. Zhang Jingbo, Zhang Yunqi. Research on the application of OBE model in practical teaching of computer specialty $[\mathrm{J}]$. Computer Knowledge and Technology, 2019(23).

3. Yao Wanyue. OBE-based "X+Business English" case teaching research $[\mathrm{J}]$. Campus English,
2018(46).

4. Yan Danping. The application of the "OBE+PAD" dual model in the teaching of college English at the threshold of core literacy [J]. Research and Practice of Innovation and Entrepreneurship Theory, 2019(5).

5. Zheng Xuezhen, Zhu Jia. An Analysis of the "Internet + Mixed" College English Teaching Model from the Perspective of Core Literacy[J]. Campus English, 2018(9): 6-7. 